ISSN (Print): 2709-9636 | ISSN (Online): 2709-9644

Volume 2, 2021(Issue III, July to September)

$$
\begin{aligned}
& \text { ثمازيم }
\end{aligned}
$$

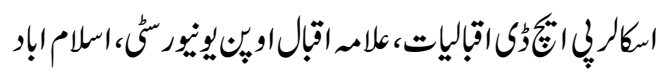

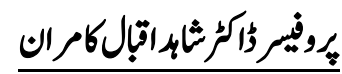

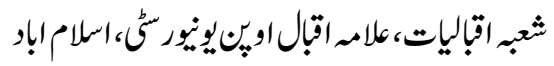

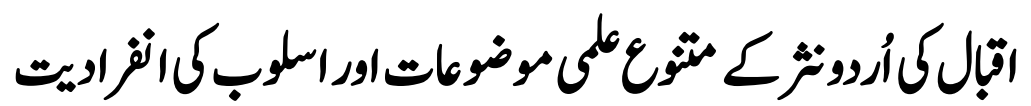

Shazia Gull

Scholar Ph.D (Iqbal Studies), AIOU, Islamabad

Professor Dr. Shahid Iqbal Kamran

Department of Iqbal Studies, AIOU, Islamabad.

\title{
The Uniqueness of Iqbal's Diverse Scholarly Themes and Style of Urdu Prose
}

The Urdu text of Iqbal is serious and diverse. Iqbal's style of Urdu writing is impressive and varied. Iqbal's Urdu text is also notable in term of eloquence and colorful language. Since the subject of Iqbal's Urdu writing are different so are the form of his, But there is also a look at the typical language and color full statement. Since the subjects of Iqbal's Urdu writing are different, so are his writing styles. Iqbal chooses his style according to his subject. He writes his essays in a lively and interesting way. Demonstrating a deep awareness of sociology in Quami- Zindagi. In his last article Iqbal expresses his views in religious, political and social way. Iqbal also writes prose in his letters according to his mind, knowledge and status of his addresses. Iqbal imagination gives life to lifeless words. This article discusses these diverse features of Iqbal's Urdu prose.

Keywords: Scholarly prose, writing style, romantic prose, fiction, plaintiff writing.

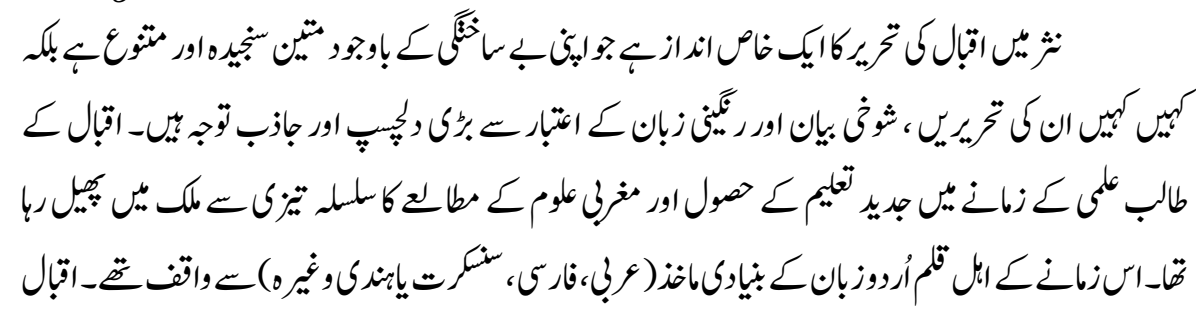




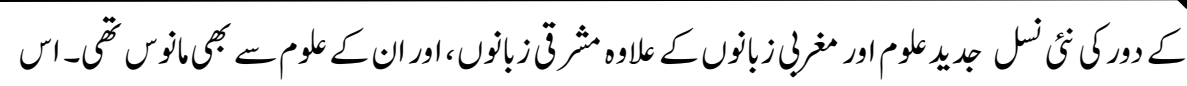

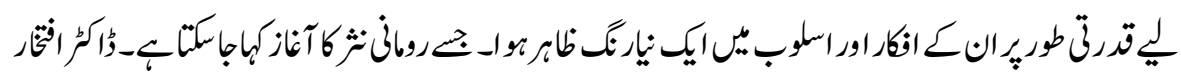

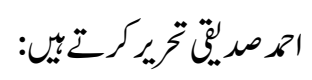

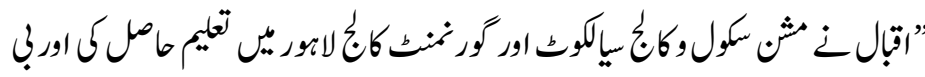

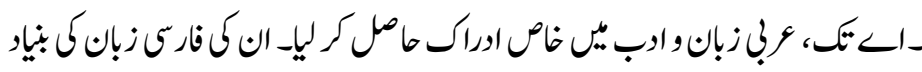

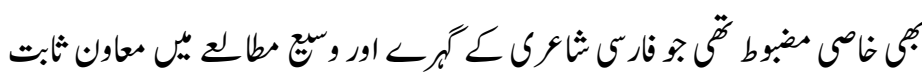

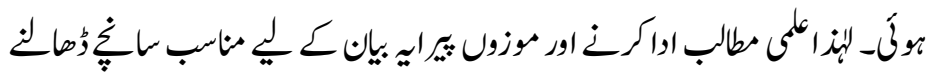

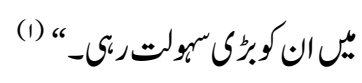

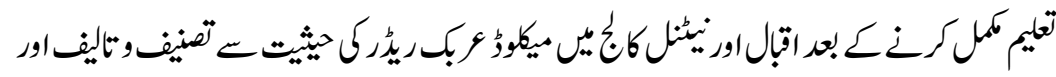

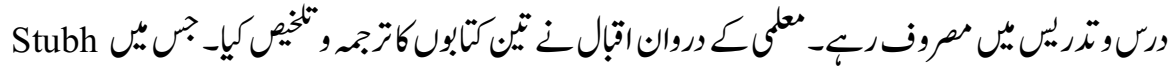

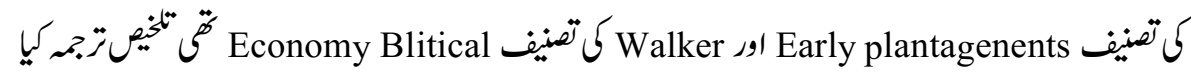

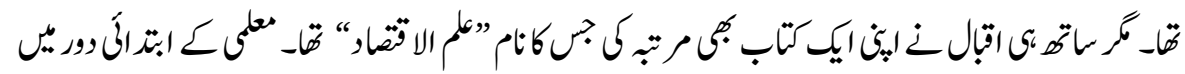

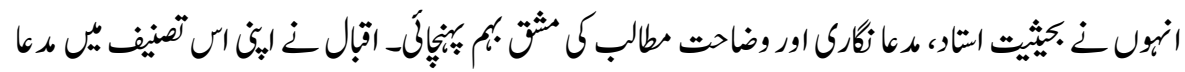

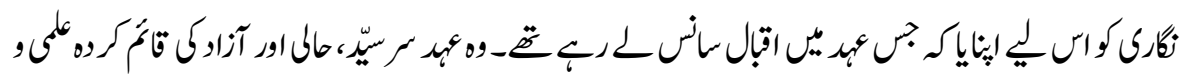

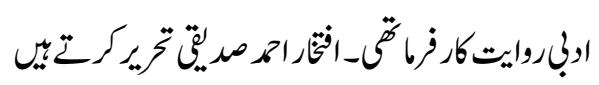

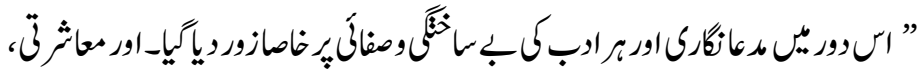

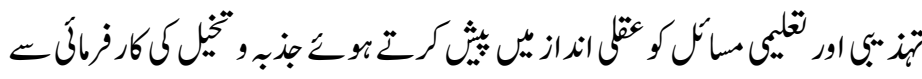

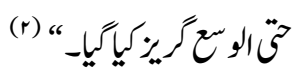

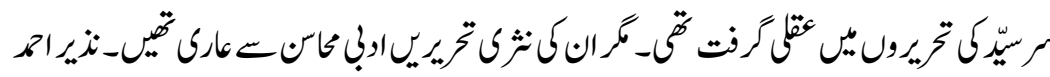

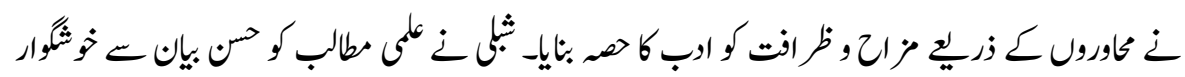

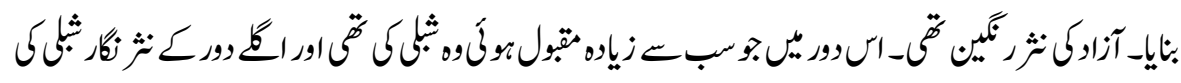

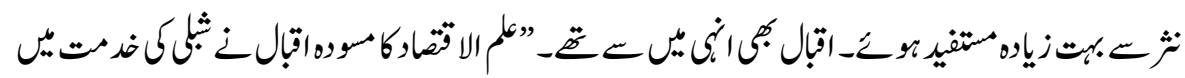




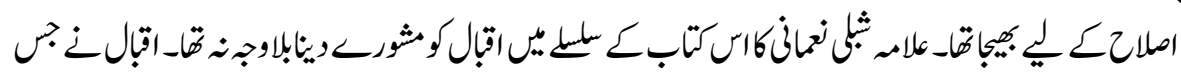

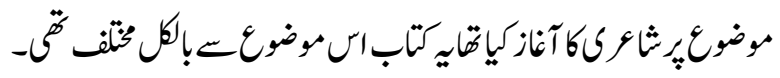

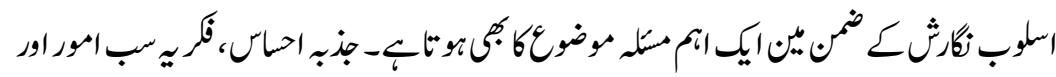

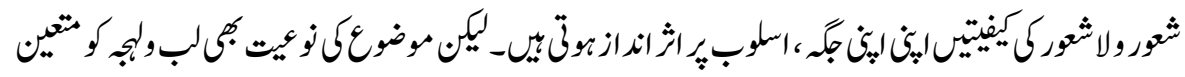

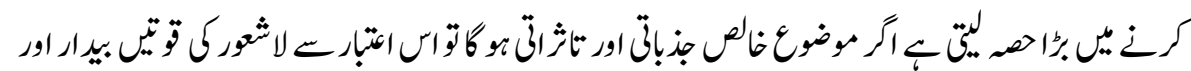

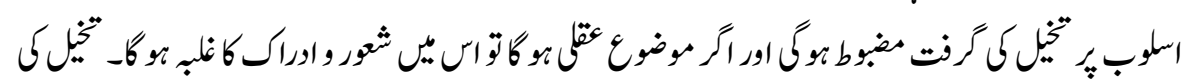

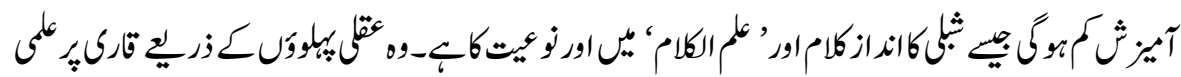

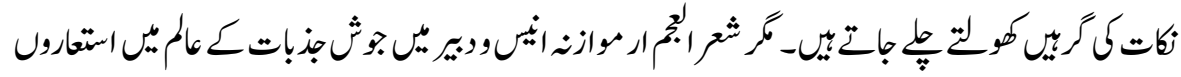

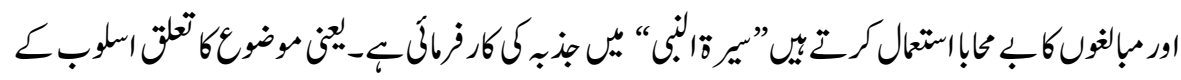

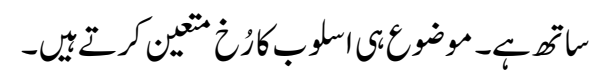

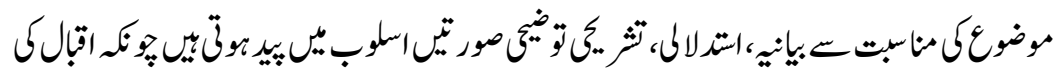

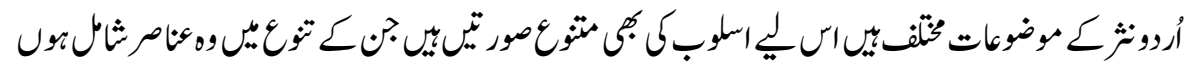

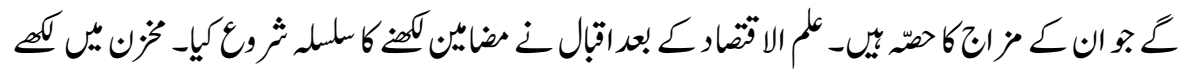

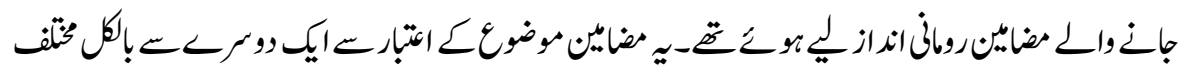

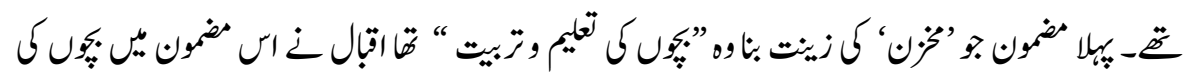

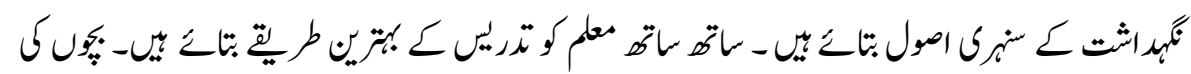

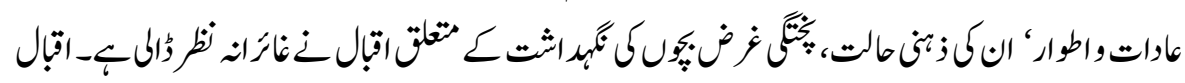

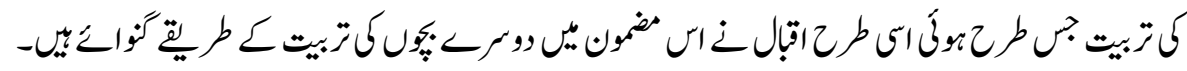

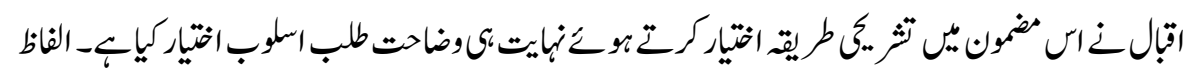

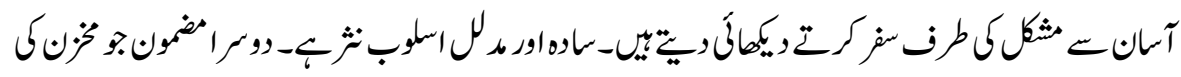

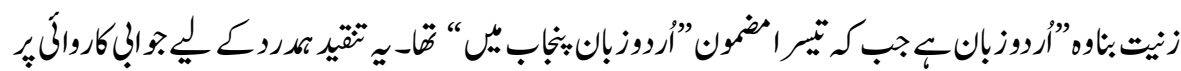

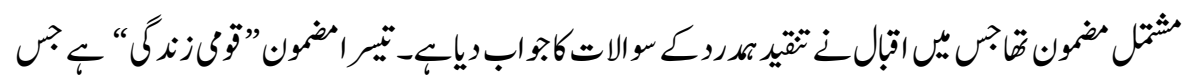

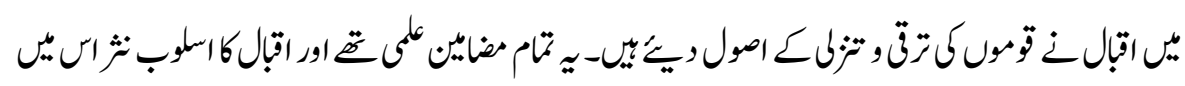




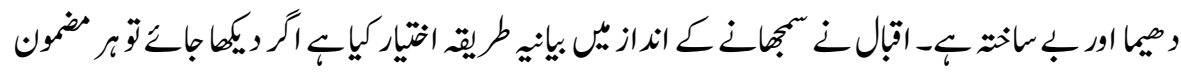

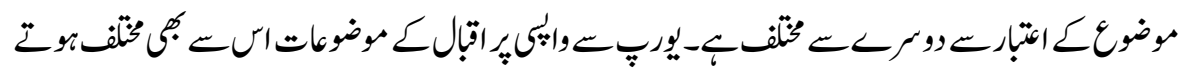

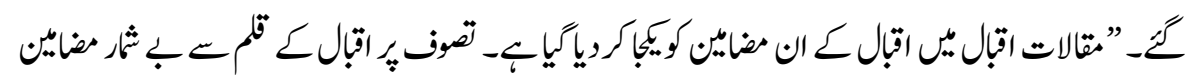

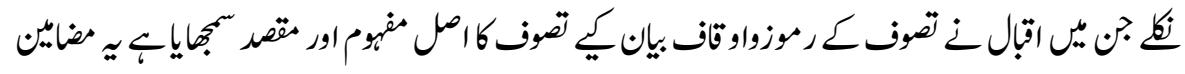

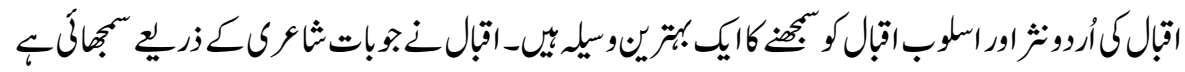

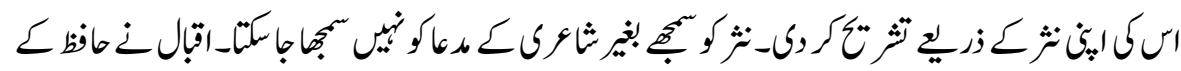

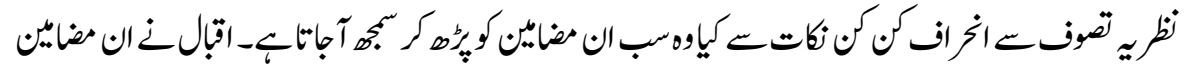

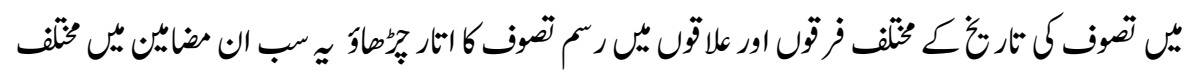

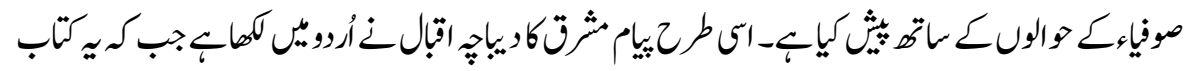

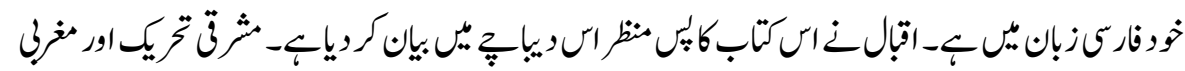

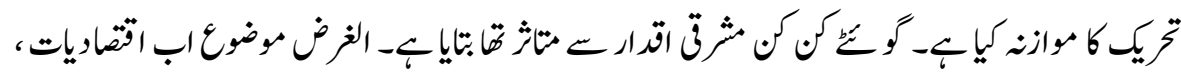

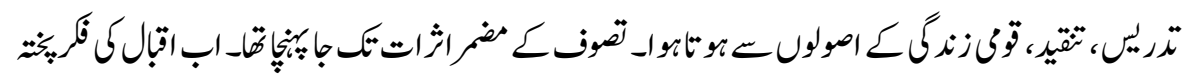

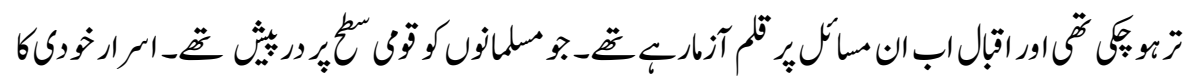

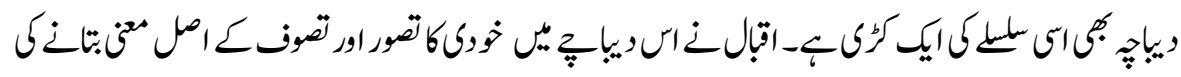

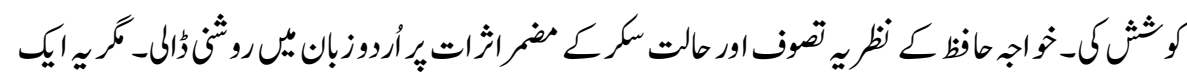

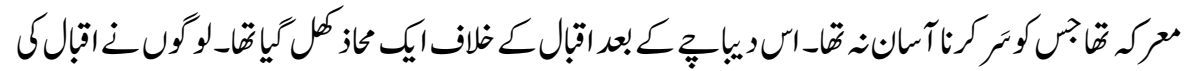

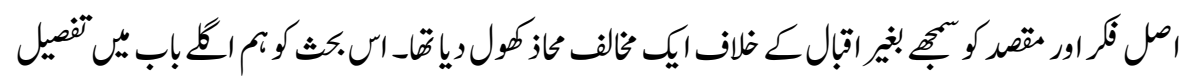

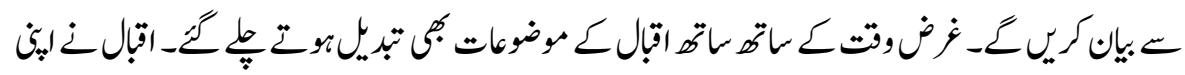

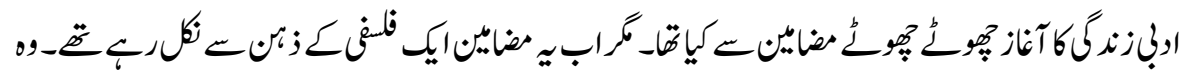

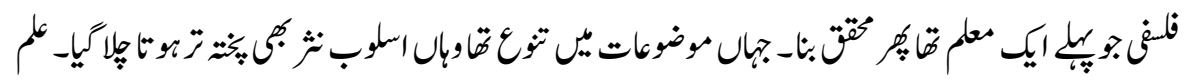

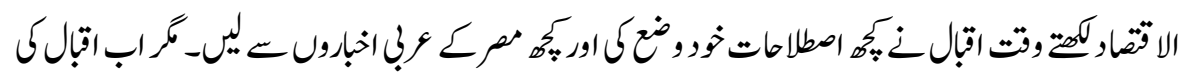

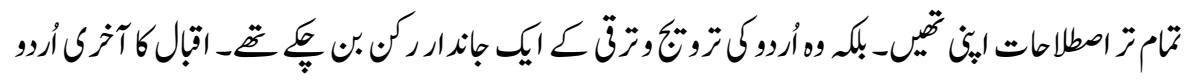

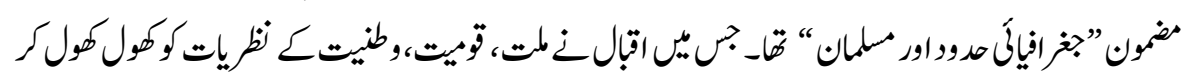




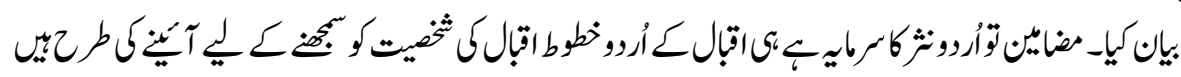

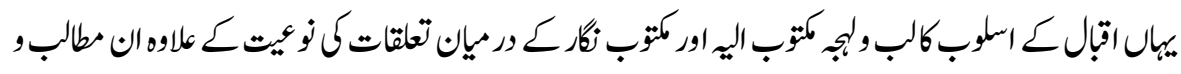

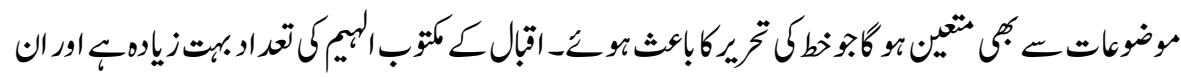

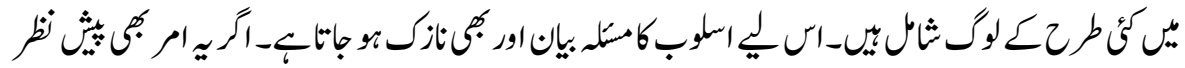

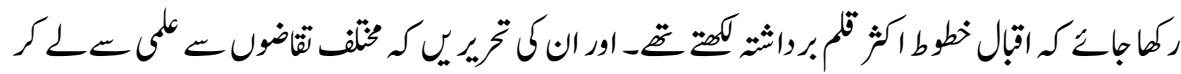

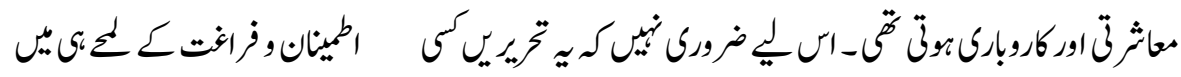

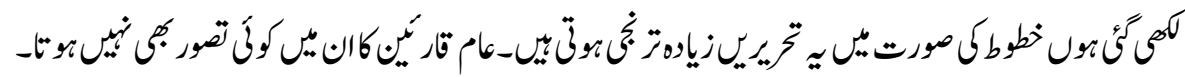

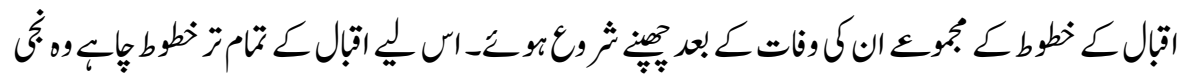

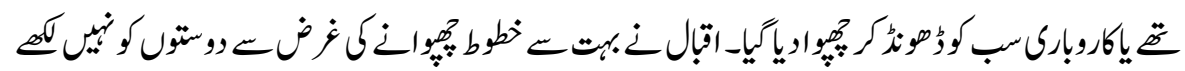

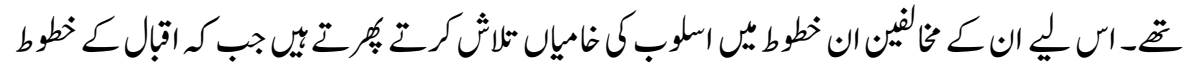

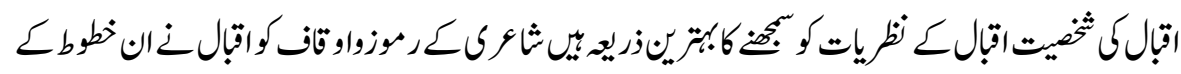

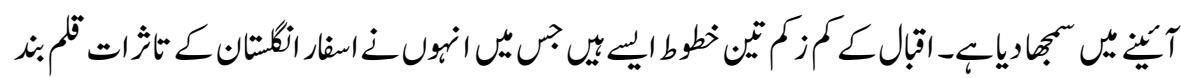

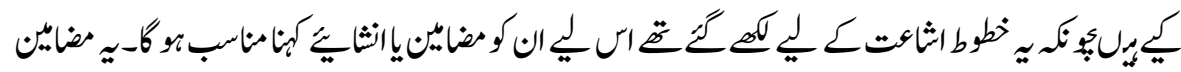

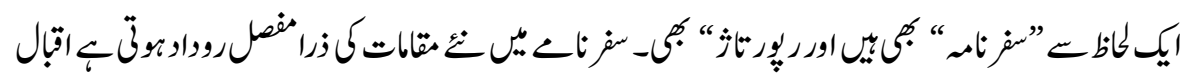

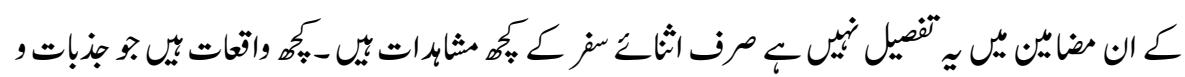

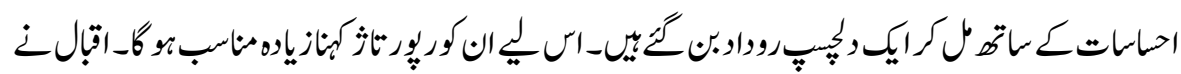

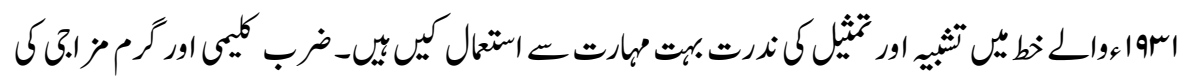

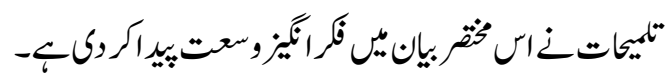

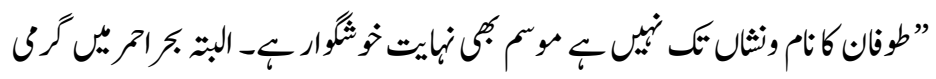

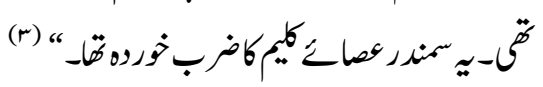

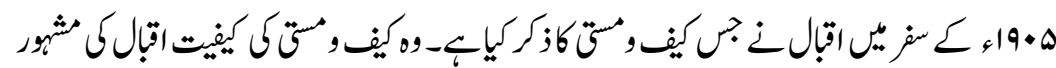

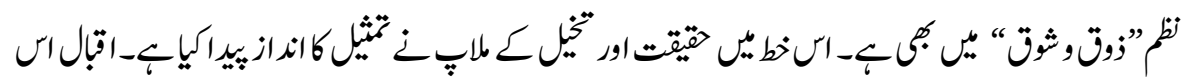


ISSN (Print): 2709-9636 | ISSN (Online): 2709-9644

Volume 2, 2021(Issue III, July to September)

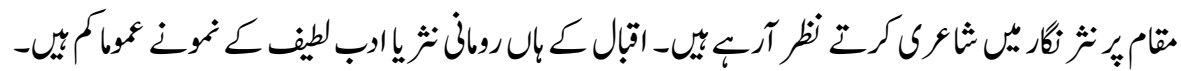

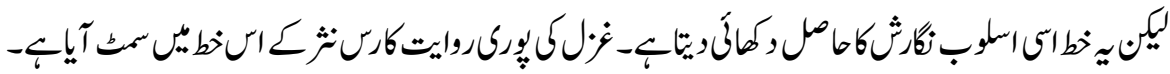

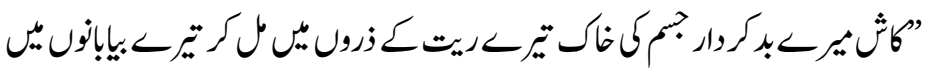

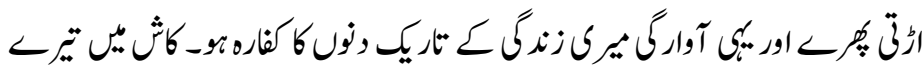

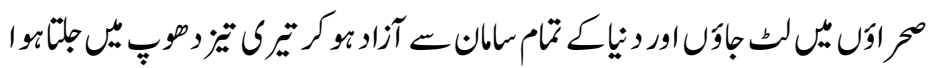

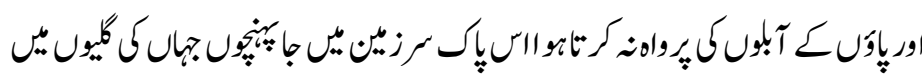

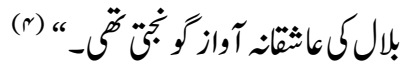

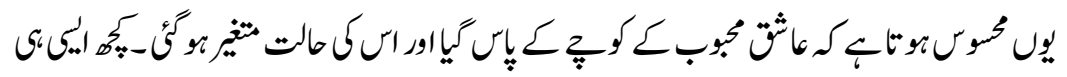

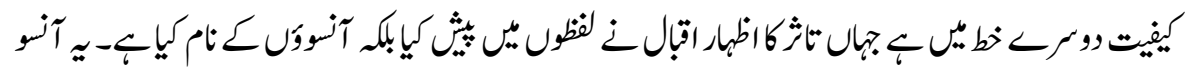

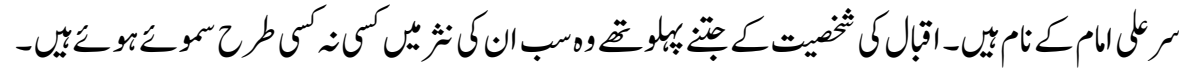

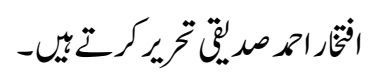

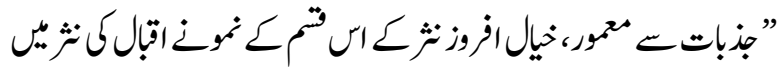

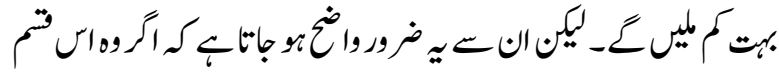

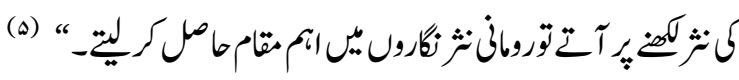

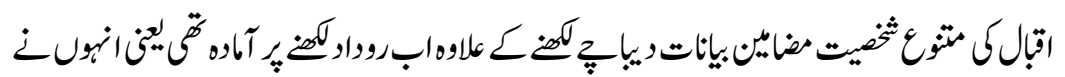

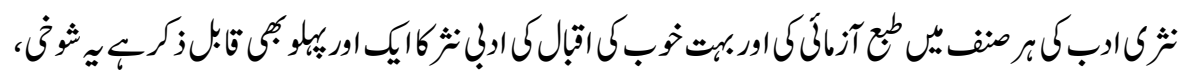

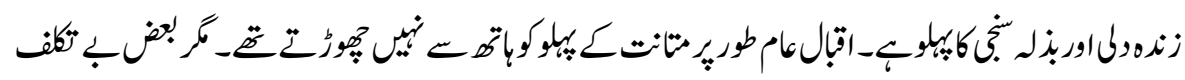

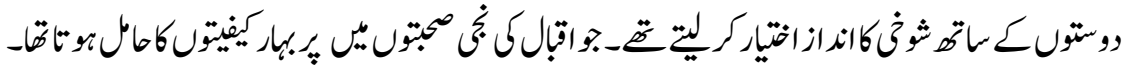

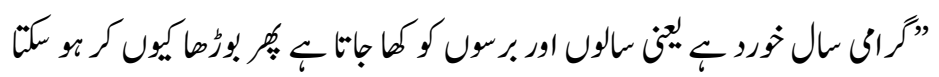

$$
(4) \lll,
$$

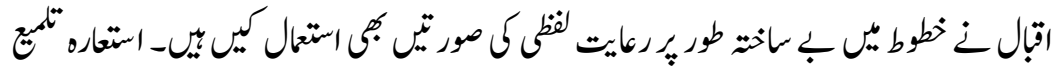

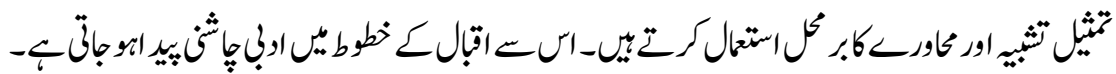




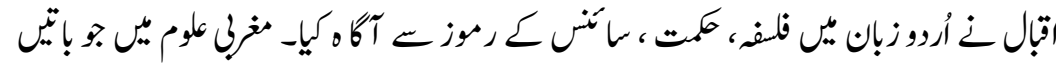

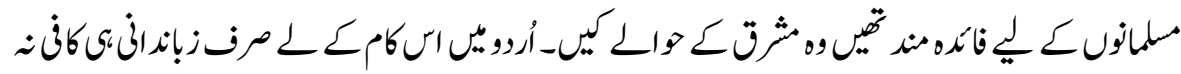

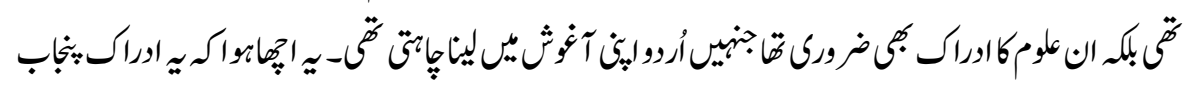

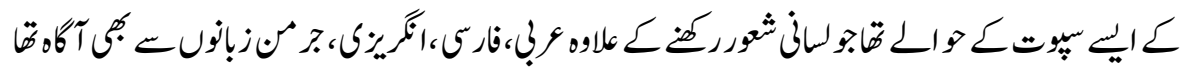

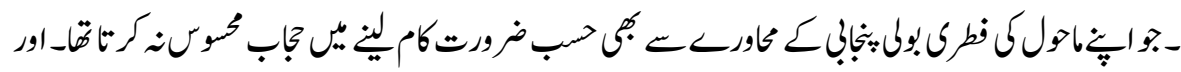

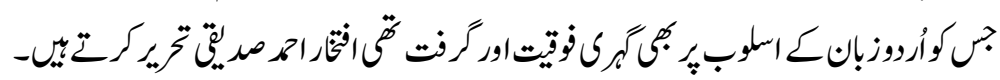

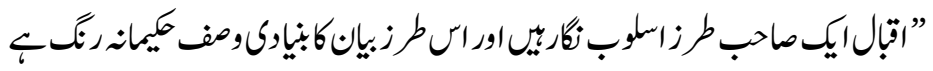

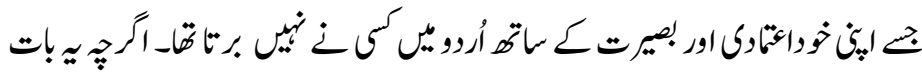

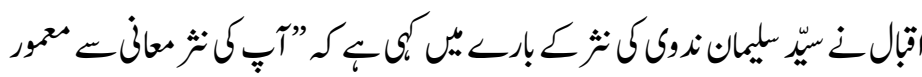

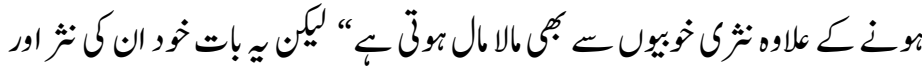

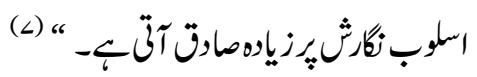
اقبالكاسلوباوراسكىانزاويت

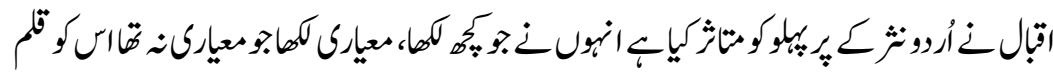

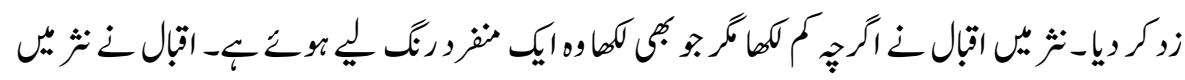

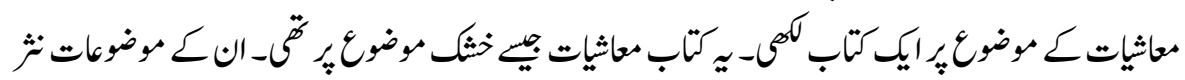

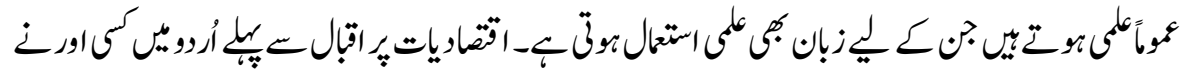

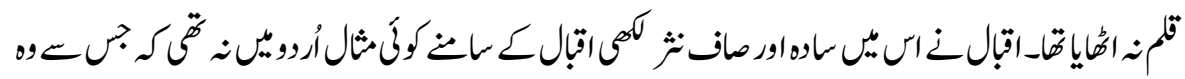

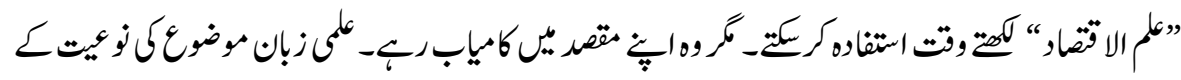

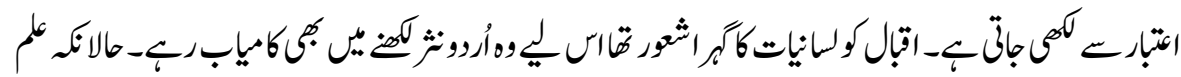

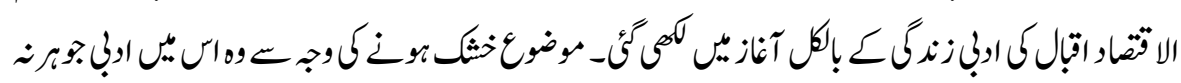

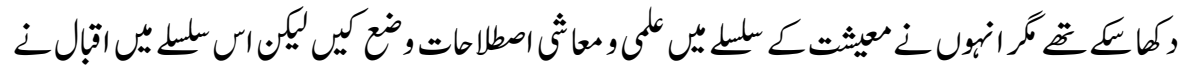

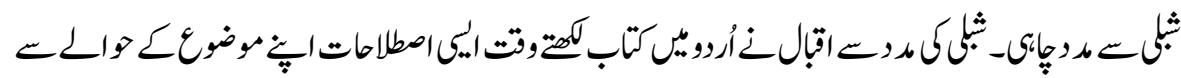

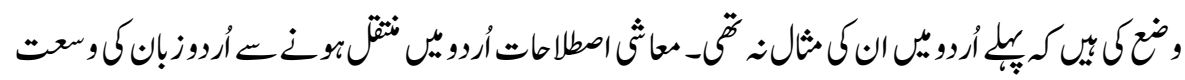


ISSN (Print): 2709-9636 | ISSN (Online): 2709-9644

Volume 2, 2021(Issue III, July to September)

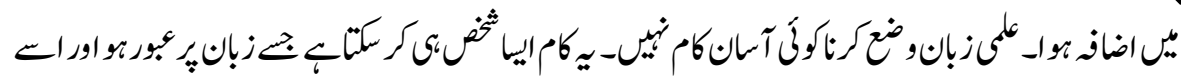

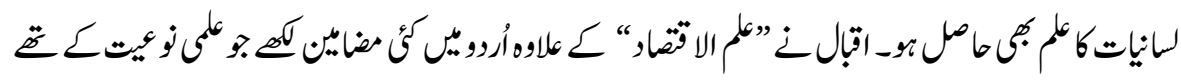

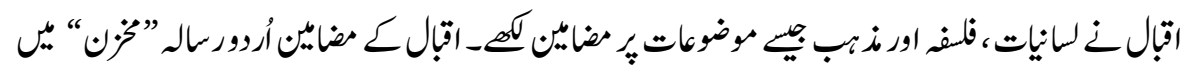

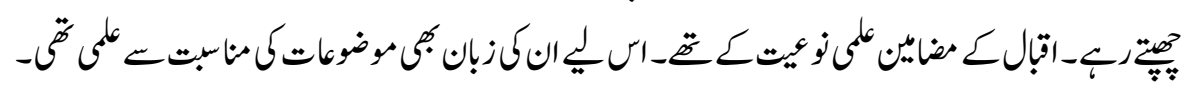

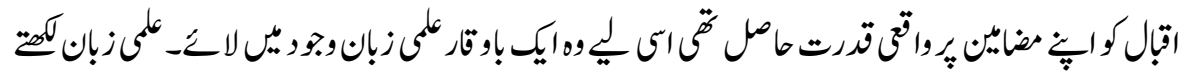

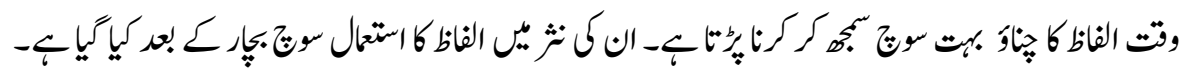

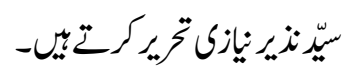

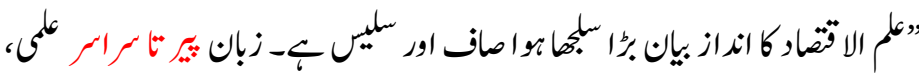

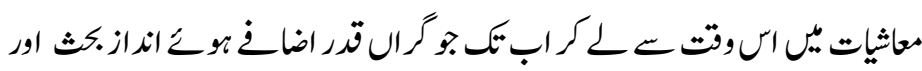

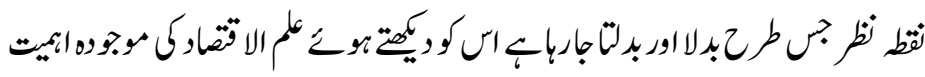

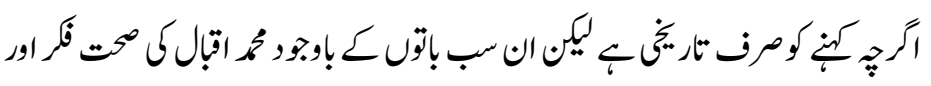

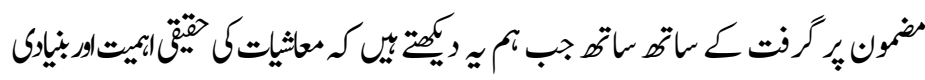

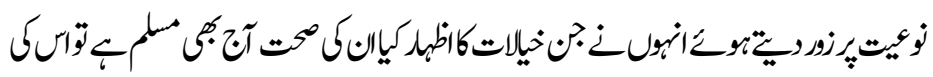

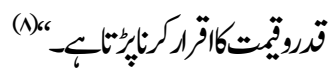

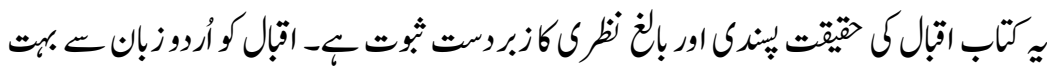

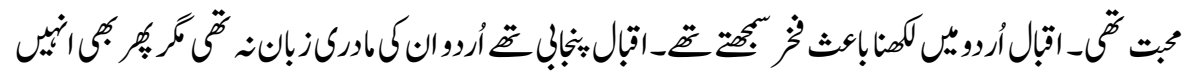

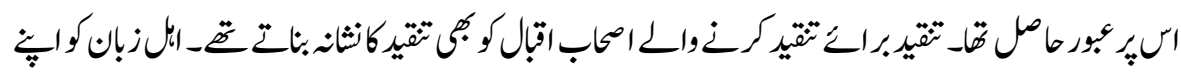

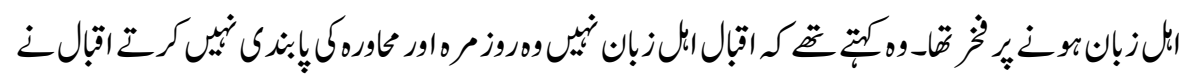

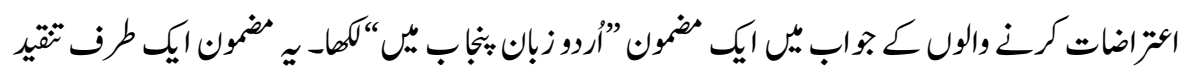

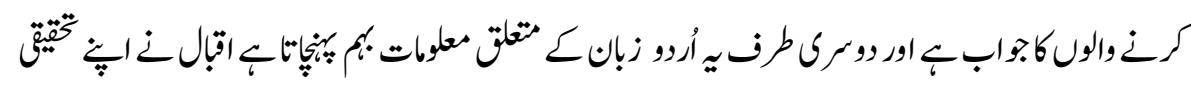

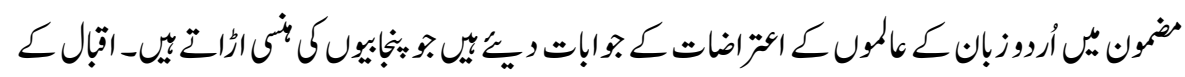

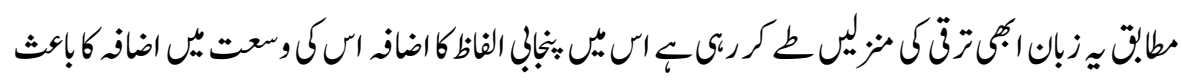

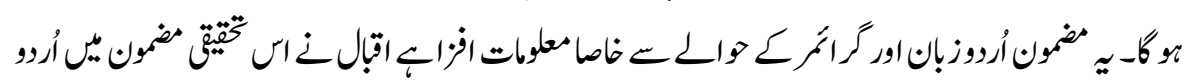




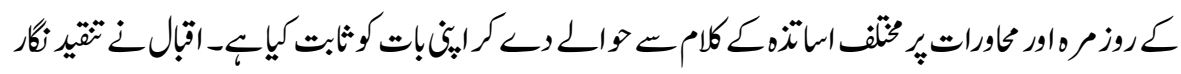

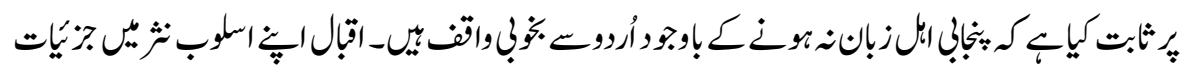

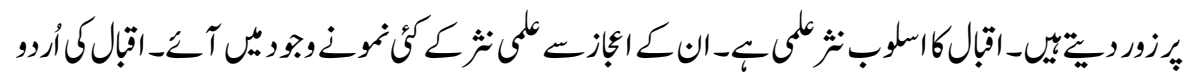

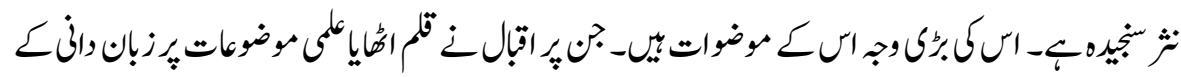

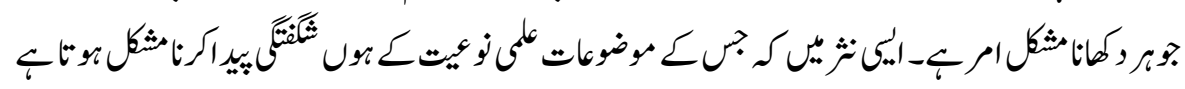

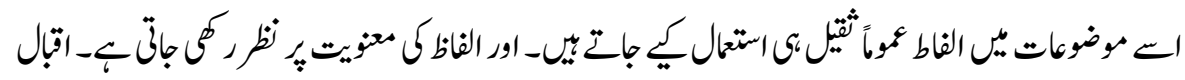

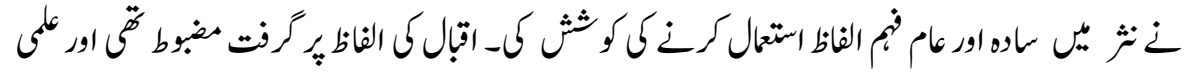

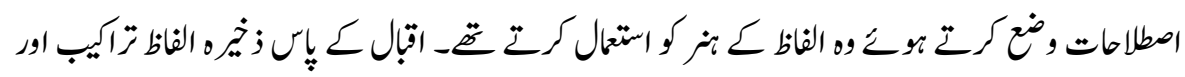

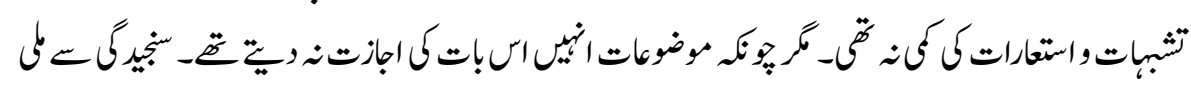

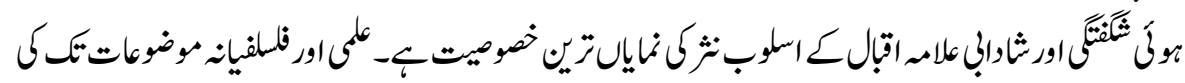

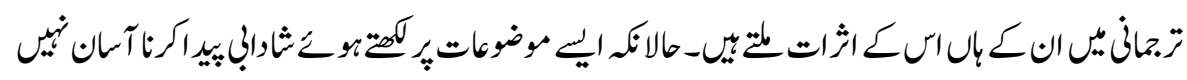

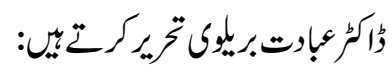

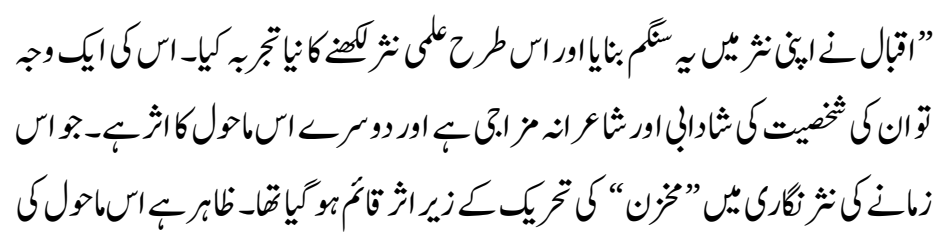

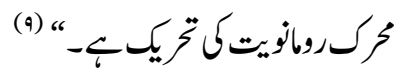

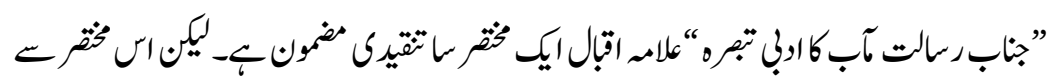

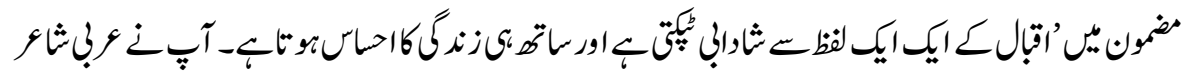

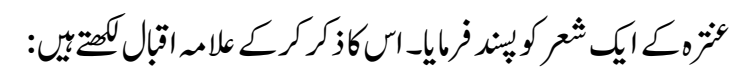

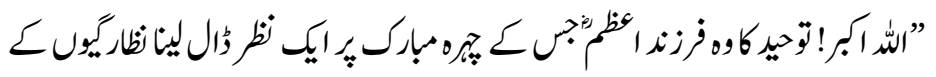

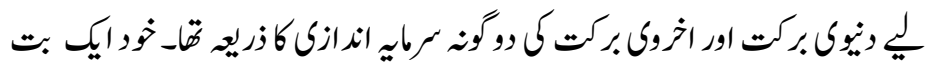

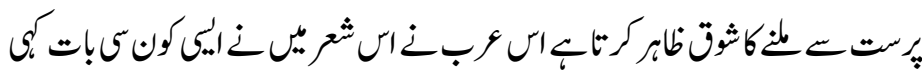




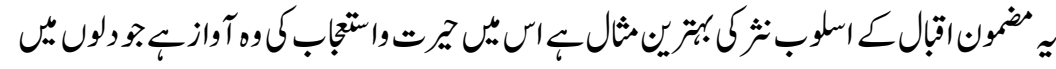

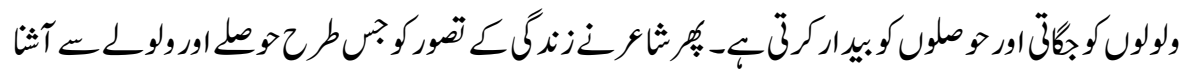

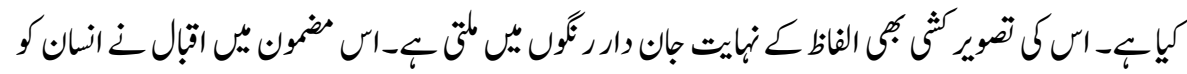

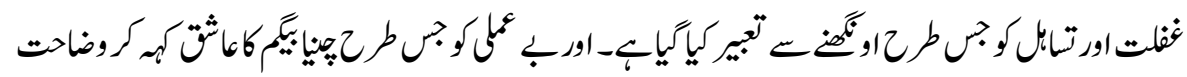

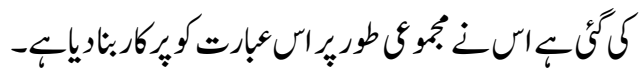

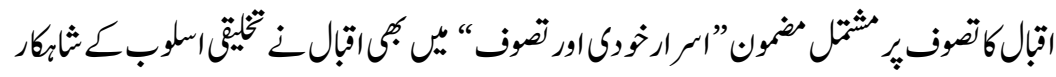

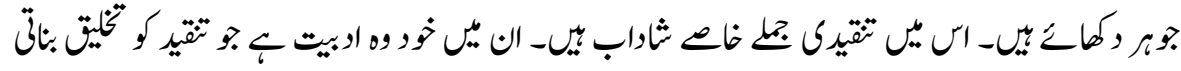

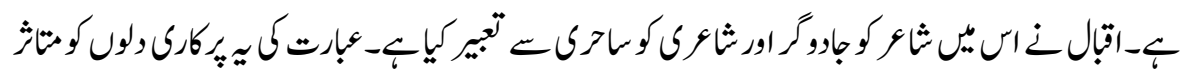

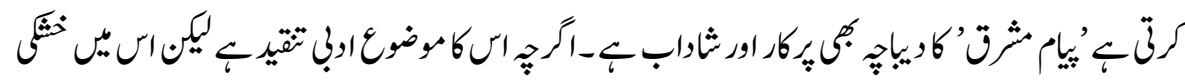

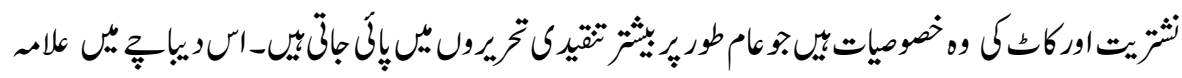

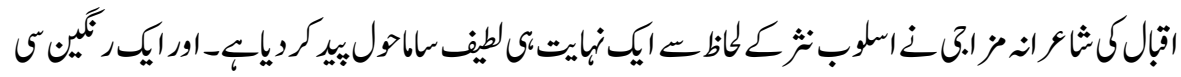

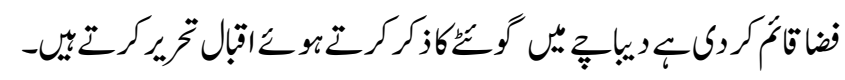

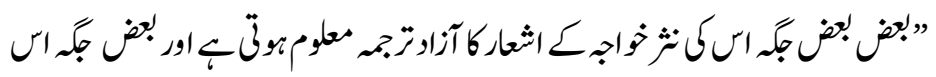

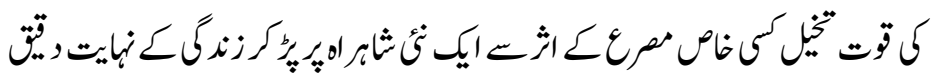

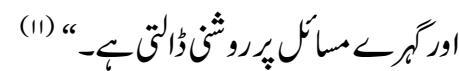

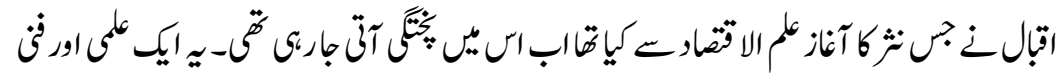

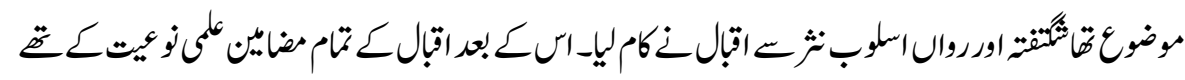

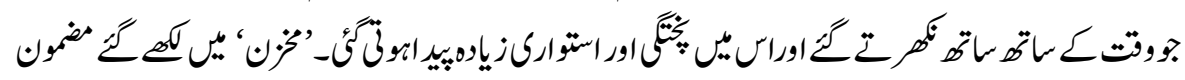

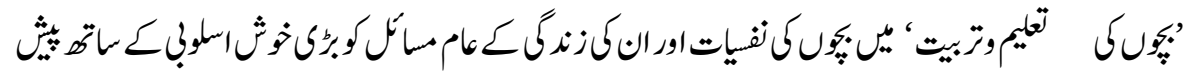

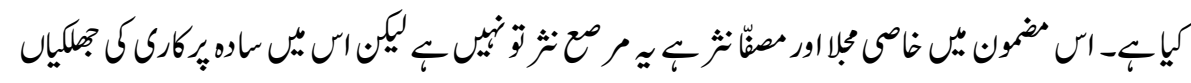

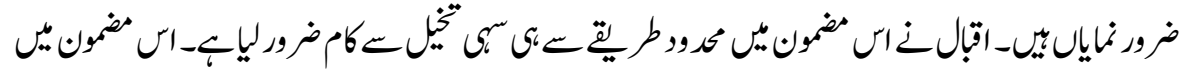

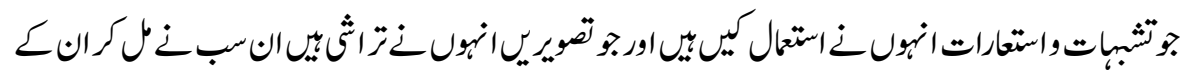

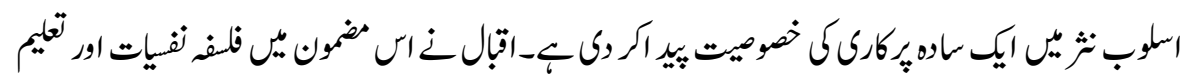


ISSN (Print): 2709-9636 | ISSN (Online): 2709-9644

Volume 2, 2021(Issue III, July to September)

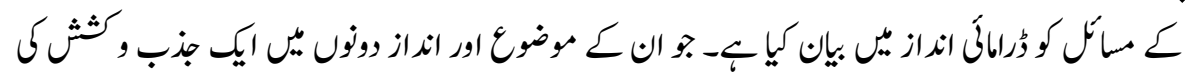

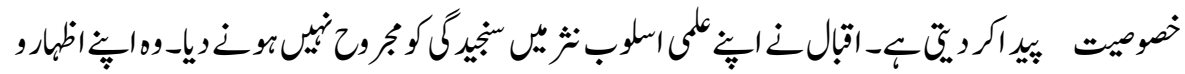

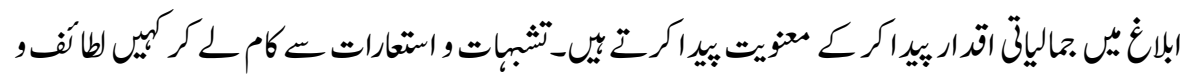

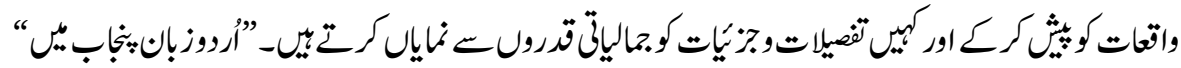

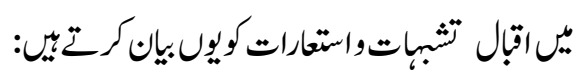

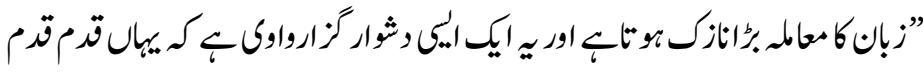

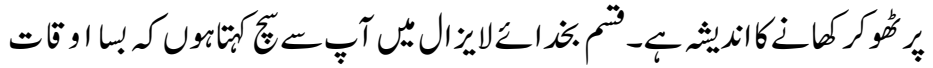

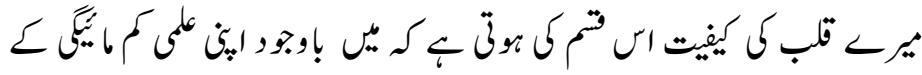

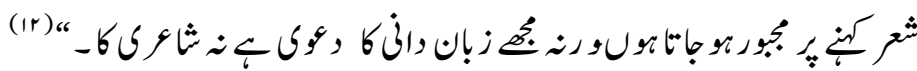

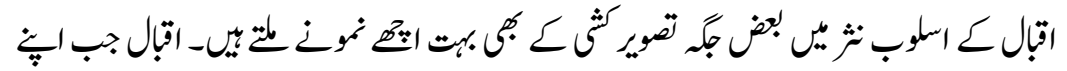

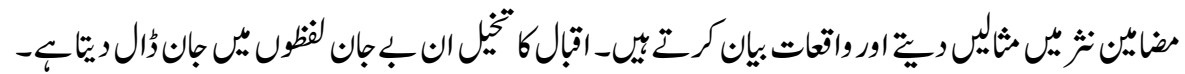

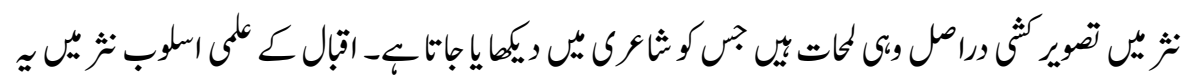

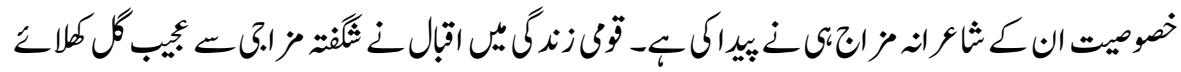

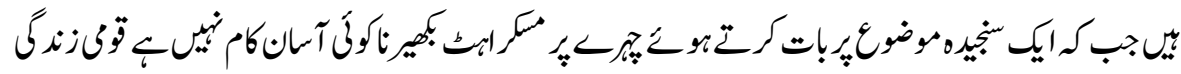

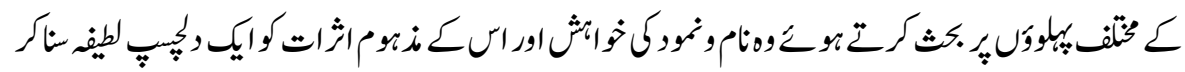
واضحكرتبن

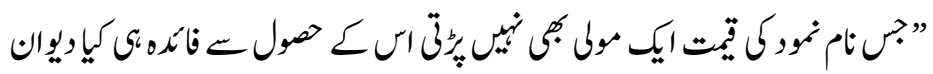

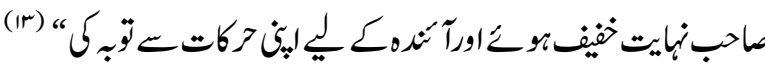

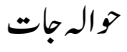

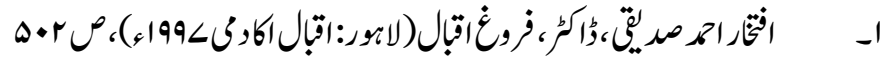

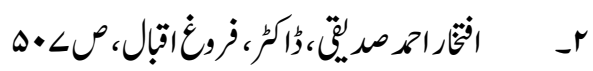

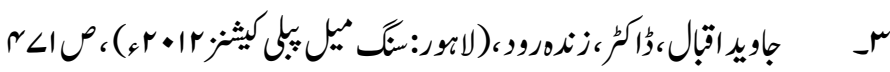

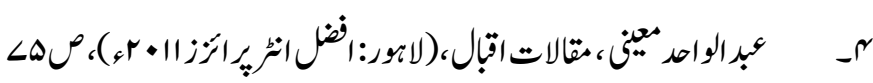


ISSN (Print): 2709-9636 | ISSN (Online): 2709-9644

Volume 2, 2021(Issue III, July to September)

$$
\begin{aligned}
& \text { (1) }
\end{aligned}
$$

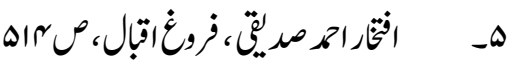

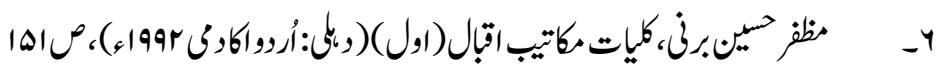

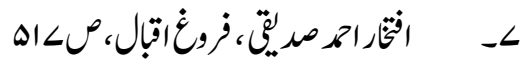

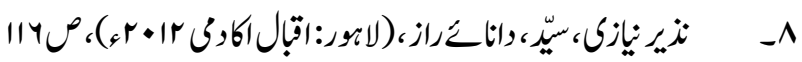

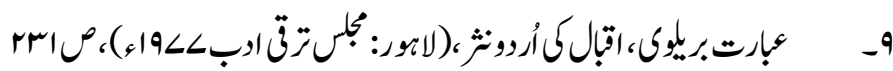

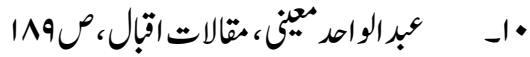

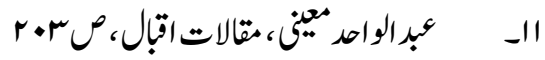

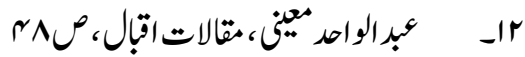

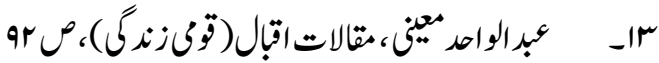

